\title{
Hypoxia Response Elements Can Cause the Overexpression of the BAX mRNA Under Hypoxic Condition
}

\author{
Ali Ghanbariasad, ${ }^{1}$ Mojgan Bandehpour, ${ }^{1,2,3}$ and Bahram Kazemi ${ }^{1,2,3, *}$ \\ ${ }^{1}$ Department of Biotechnology, School of Medicine, Shahid Beheshti University of Medical Sciences, Tehran, IR Iran \\ ${ }^{2}$ Cellular and Molecular Biology Research Center, Shahid Beheshti University of Medical Sciences, Tehran, IR Iran \\ ${ }^{3}$ Department of Biotechnology, School of Advanced Technologies in Medicine, Shahid Beheshti University of Medical Sciences, Tehran, IR Iran \\ "Corresponding author: Bahram Kazemi, Cellular and Molecular Biology Research Center, Shahid Beheshti University of Medical Sciences, Tehran, IR Iran. Tel: +98-2122439956, \\ Fax: +98-2189784665, E-mail: bahram_14@yahoo.com
}

Received 2015 October 31; Revised 2015 December 22; Accepted 2016 September 24.

\begin{abstract}
Background: Suicide gene therapy is one of the modern methods of cancer treatment. However, transmission for tumor cells is one of the main challenges to overcome. Hypoxia is a common phenomenon in solid tumors that lead to changes in tumors microenvironment. Hypoxia-responsive element sequences are regulatory sequences that lead to activation of their upstream and downstream genes in hypoxic time. Bax is a strong proapoptotic gene that causes apoptosis in the time of over expression in cells. Objectives: The aim of this study is to use this sequence in order to specify suicide gene therapy by the help of a gene producing Bax protein under control of CMV promoter.

Methods: The gene of BAX, BAX3HRE and 3HRE were cloned into interested vectors. In the next step, the function of HRE sequence on over expression of upstream gene under hypoxic condition was evaluated through western blot, MTT assay and real time PCR. Results: The results of this study indicate that cells transected by pcDNA3.1/BAX 3HRE. The rate of apoptosis in them significantly increased in comparison with pcDNA3.1/BAX in hypoxic conditions.

Conclusions: Regarding the role of HREs in increasing the expression of its upstream genes, it can be used to specify suicide gene therapy in treatment of solid tumors.
\end{abstract}

Keywords: Bax Protein, Gene Therapy, Tumor

\section{Background}

Suicide gene therapy is one of the interesting methods of gene therapy that recently has drawn lots of interest to itself in research. By definition suicide gene therapy is a method in which vector containing killer gene is transferred into the target cell and after the gene expression in the given cell, the cell is moved toward apoptosis or necrosis (1). Of different types of killer genes identified up to now, the genes encoding proteins such as P53, E1A, P202, PEA3, BAX, Bik and enzymes metabolizing drugs such as thymidine kinas and cytosine deaminase $(2,3)$.

Bax is a proapoptotic gene that causes apoptosis when over-expressed in cell lines such as prostate, colon, cervical, and ovarian cancers (4).

Although lots of research has been done related to the suicide gene therapy, there are different challenges to overcome. The limitation of expression of killer genes in tumor cells is one of these challenges. One of the applied solutions is the use of specific promoters of tissue and tumor like human telomerase reverse transcriptase (5) and Survivin (6). However, the main problem of these promoters is their low efficiency. Some researchers are working on virus promoters like SV40 and CMV that benefits of high efficiency (7). However, these promoters do not have any specific targeting for tumor cell. It is activated in all tissues to some extent. To have a specific promoter, Hypoxiaresponsive element (HRE) can be attached to virus promotores. HRE sequences are sequences that are located upstream or downstream of different genes and function as enhancers in hypoxia conditions on downstream and upstream promoters (8).

Binley et al. could achieved a targeted and specific expression of human cytochrome p450 in breast tumors in hypoxia conditions through the combination of HRE element and SV40 promoters (9).

Hypoxia is a common phenomenon in solid tumors that lead to changes in tumors Microenvironment (10), when the size of tumor reaches to $44 \mathrm{~mm}$ in tumor cells this phenomenon occurs (11). Factor HIF-1 provides molecular basis for cancer cells' adaptation under hypoxia conditions that are necessary for tumor progression in becoming malignant $(12,13)$. 
Under normal oxygen conditions, HIF-1 $\alpha$ (Hypoxiainducible factor 1-alpha) is rapidly degraded by Pathway, but under hypoxic conditions this action is prevented and results in HIF-1 $\alpha$ accumulation in the nucleus. HIF$1 \alpha$ and HIF- $1 \beta$ form heterodimer and are attached to hypoxia response element (HRE) which consequently activates more than 50 genes that have HRE in upstream or downstream of their gene sequence and facilitate the genes' transcription (8), for example, nitric oxide, vascular endothelial growth factor (VEGF) (13), DEC1, DEC2 (14), Nitric Oxide (15), Nuclear Clustrin (16), human plasminogen activator inhibitor-1 (PAI-1) (17), erythropoietin (EPO), glucose transporter-1 (GLUT-1) and phosphoglycerate kinase (PGK) (18). The HRE-inducible sequence allows a tight regulation of events, switching-on at low oxygen tension but switching-off under reoxygenation (19).

The balance between poroapoptotic molecules like BAX and anti-apoptotic ones like BCL-2 play an important role in forming apoptosis in cancer cells. In order to enhance specifically the expression of Bax gene in MCF-7 cell line in hypoxic condition. we used 3HRE sequence (GTCGTGCAGGACGTGACATCTAGT) (18) for the first time to specify CMV promoter action to express BAX gene in cancer cells that have suffered from hypoxia.

\section{Methods}

\subsection{Cell Culture}

The MCF-7 (Breast Cancer Cell Line) was cultured with RPMI1640 (Gibco, USA) media supplemented with 10\% fetal bovine serum (FBS), $100 \mathrm{u} / \mathrm{mL}$ of penicillin and $100 \mathrm{u} / \mathrm{mL}$ streptomycin at $37^{\circ}$ in a humidified incubator under $5 \%$ $\mathrm{CO} 2$.

\subsection{Hypoxic Condition}

Hypoxia was obtained by an aerobic incubator (Memmert, GERMANY). Cells were incubated under 5\% CO2, 94\% $\mathrm{N} 2,1 \% \mathrm{O} 2$ and $37^{\circ}$ for 36 hours.

\subsection{Plasmid Construction}

BAX gene (Accession Number NM138764.4) with 3HRE from PGK(Phosphoglycerate kinase) gene in the 3' end was synthesized and cloned in the treading vector. This synthesized gene was sub cloned into the pcDNA 3.1 vector using NheI and ApaI restriction enzyme as a result making PcDNA3.1/BAX 3HRE. For construction of pcDNA3.1/Bax, PCDNA3.1/BAX 3HRE was digested with HindIII restriction enzyme; therefore, 3HRE was eliminated and pcDNA3.1/BAX was made.

HRE primers were synthesized (Table 1). 3HRE was amplified with PCR and PCR products were recovered with gel extraction kit subsequent at $2 \%$ agarose gel electrophoresis. The fragments were ligated in the downstream of GFP gene in the pEGFP-N1 vector. pEGFP-N1 vector was used as control the same as pcDNA3.1 vector (20).

\subsection{Transfection}

Cells were plated into 24-well dishes and grown for 24 hours to reach $70 \%$ - 90\% confluence. Two sets of wells in duplicate were prepared for each plasmid sample. Cells were transfected with lipofectamin 2000 (Invitrogen, USA) according to manufacturer's instructions.

\subsection{MTT Assay}

Cell viability was determined with [3-(4, 5dimethylthiazol-2-yl)-2, 5-diphenyltetrazolium bromide] MTT. Briefly, cells were incubated for 36 hours, after that MTT solution $(1 \mathrm{mg} / \mathrm{mL})$ was added on to each well and incubated for 2 hours at $37^{\circ} \mathrm{C}$. The crystals were dissolved in $200 \mu \mathrm{L}$ DMSO and the extent of reduction of MTT was determined as the absorbance at $470 \mathrm{~nm}$. Wells with complete medium and MTT but without cells were used as blanks (21).

\subsection{Western Blot}

Incubated cells were harvested after 36 hours and lysed with a lysis buffer. The lysate was sonicated and boiled at $80^{\circ} \mathrm{C}$ for 5 minutes. Total proteins were separated by $15 \%$ SDS-PAGE and transferred to PVDF membrane. Following this transfer, membrane was blocked with $5 \%$ skim milk in Tris-buffered saline with tween 20 (TBST). The membrane was incubated with mouse anti-GFP monoclonal antibody (Roche) for 2 hours and washed with TBST for 3 times. It was then incubated with HRP-conjugated secondary antibody for 2 hours. After washing with TBST for 3 times the immune complex was visualized with the NBT/BCIP. $\beta$-actin was used as a control.

\subsection{Real Time PCR}

Total cellular RNA was isolated with Kit (Fermantas,Lithuania) and cDNA was synthesized with Kit (Bioneer,Republic of Korea). Real Time PCR was performed in a reaction mixture containing cDNA. Specific primer (Table 1) and SYBRGREN master mix (Bioneer,Republic of Korea) was used in reaction. The amplification was performed in a Corbet research rotor gene. The PCR reaction was used as 94 for 10 minutes, 94 for 30 seconds and 60 for 30 seconds for 35 cycles. GAPDH was used as a control. 
Table 1. Primers Were Used in This Study

\begin{tabular}{lcc}
\hline & Forward Primer & Revers Primer \\
\hline Primer for proliferation of HRE & $5^{\prime}$-CCAAGCTTGTCGTGCAGG-3' & $5^{\prime}$-TTAAGCTTGCTGTCACGTCC-3' \\
BAX for real time PCR & $5^{\prime}$-TGGAGCTGCAGAGGATGATTG-3' & $5^{\prime}$-GAAGTTGCCGTCAGAAAACATG-3' \\
GFP for real time PCR & $5^{\prime}$-ACAACTACAACAGCCACAACG-3' & $5^{\prime}$-GGTCACGAACTCCAGGAG-3' \\
GAPDH for real time PCR & $5^{\prime}$-GAAGGTGAAGGTCGGA GTC-3' & $5^{\prime}$-GAAGATGGTGATGGGATTTC-3' \\
\hline
\end{tabular}

\section{Results}

\subsection{Construction of Vectors}

BAX gene containing 3 copies of HRE sequence was cloned into expression vector pcDNA3.1. In the next step, HRE was removed from synthesized fragment cloned into pcDNA3.1 using HindIII enzyme. The cloning of two segments was verified by PCR and sequencing.

To make pEGFP N1 / 3HRE, at first, HRE was amplified by PCR reaction using primers (Table 1 ) that have enzyme identification site in their 5' sides and after that, this sequence was cloned into downstream of GFP gene in vector pEGFP-N1 in NotI region and its proper presence and direction was confirmed by the help of PCR and sequencing (Figure 1).

\subsection{HRE Can Enhance Transcription of Genes That Located in Its Upstream}

In this study it was proved with Real time PCR that HRE sequence can increase the expression of its upstream genes. As it is shown in Figure 2, there was a significant increase in the rate of mRNA expression of BAX gene in MCF7 cell line transfected with pcDNA3.1/BAX3HRE in comparison with cells transfected with pcDNA3.1 / BAX under hypoxic conditions for $36 \mathrm{~h}$. The same results were obtained when PEGFP-N1 and PEGFP-N1 / 3HRE were compared (Figure 2).

In order to prove the increase of GFP gene expression, western blot was used. As it is depicted in Figure 3 the results obtained by western blot verifies real time results again (Figure 3 ).

3.3. Investigation of Apoptosis in MCF-7 Cells That Were Transfected with pcDNA3.1/BAX and pcDNA3.1/BAX3HRE Under Hypoxia Conditions

MTT assay was used to assess transfected cells viability with vectors pcDNA3.1 / BAX and pcDNA3.1/BAX 3HRE.VectorpcDNA3.1 was used as a negative control.

Although cell death has occurred in transfected cells with pcDNA3.1 /BAX under hypoxic conditions, there was a rate of more than $95 \%$ cell death in cells that transfected with pcDNA3.1 /BAX 3HRE vector (Figure 4).

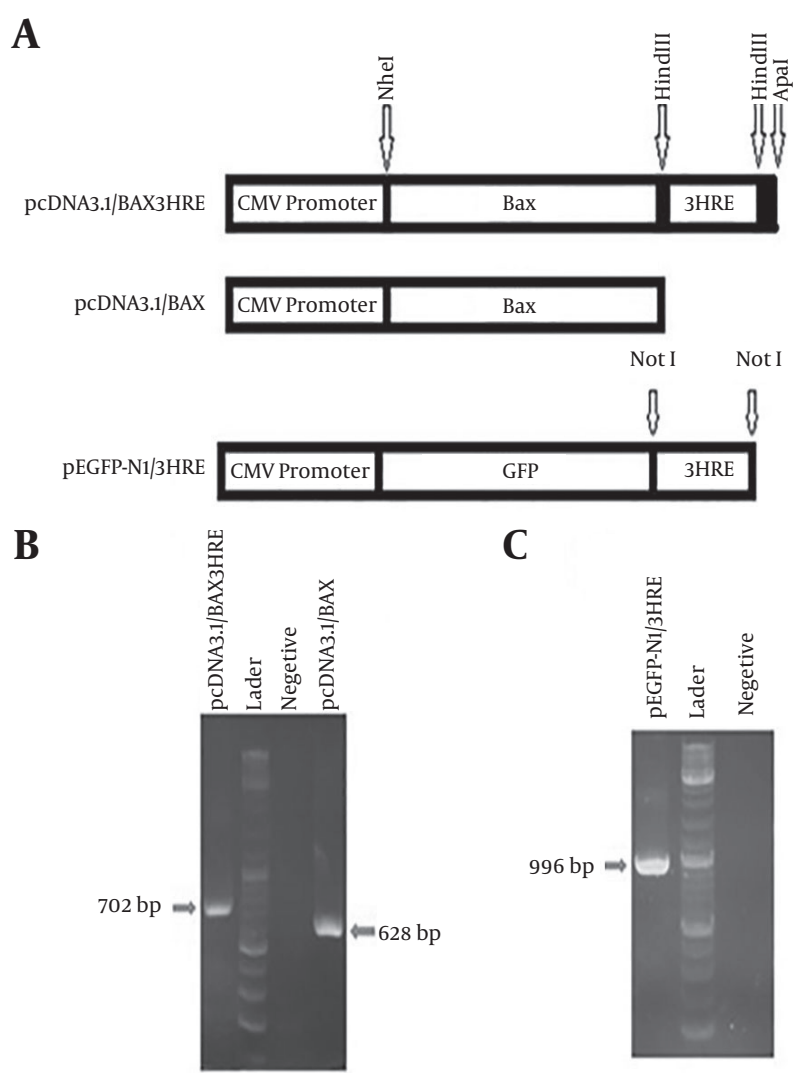

Figure 1. Making of consract.1A schematic diagram showing the constracts.1B/verification of cloning BAX3HRE and BAX in the pcDNA3.1 vector with universal primer.1C/ verification of cloning 3 repetitive of HRE in downstream of GFP gene in the pEGFP-N1 vector with universal primer.

\section{Discussion}

At first the effect of HRE sequences on increase of mRNA expression of BAX and GFP genes was investigated in MCF-7 cell line using Real Time PCR. The increase of expression of BAX gene along with high increase of apoptosis in MCF7 cell line transfected with pcDNA3.1/BAX3HRE under hypoxic condition can be related to the effect of $3 \mathrm{HRE}$ sequence located in downstream of gene.

Hypoxia is a common phenomenon of solid tumors. 


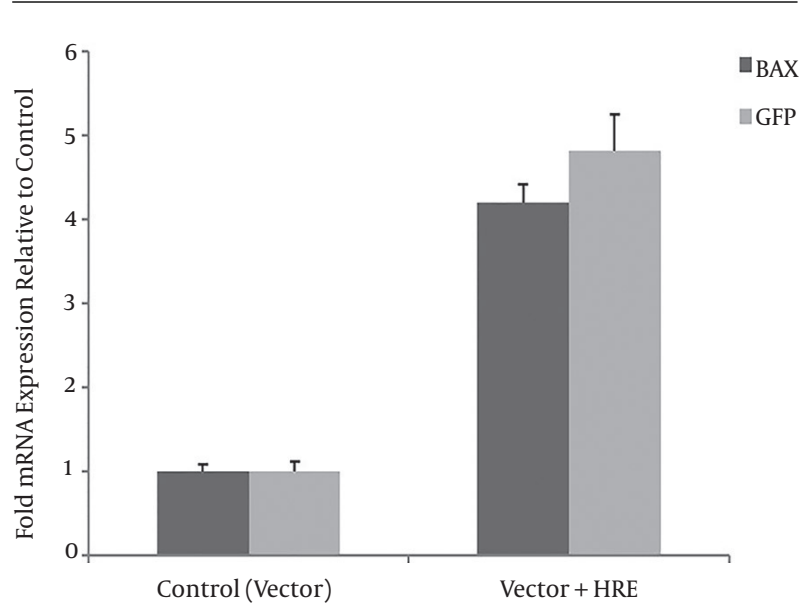

Figure 2. BAX and GFP mRNA expression in MCF7 cell line transfected by pCDNA3.1/BAX 3HRE and pEGFP-N1/3HRE (HREs group) and pcDNA3.1/BAX and pEGFP$\mathrm{N} 1$ (without HREs = control group). BAX and GFP mRNA expression is significantly increased $\left({ }^{*} \mathrm{P}=0.016\right.$ and $\left.{ }^{* *} \mathrm{P}=0.011\right)$ in the HRE group compared with control group $(n=3)$. Student's t-test was used for analysis. Data shown is mean values \pm standard deviation (SD).

Figure 3. Western Blot Analysis of the Expression of GFP in MCF7 Cells

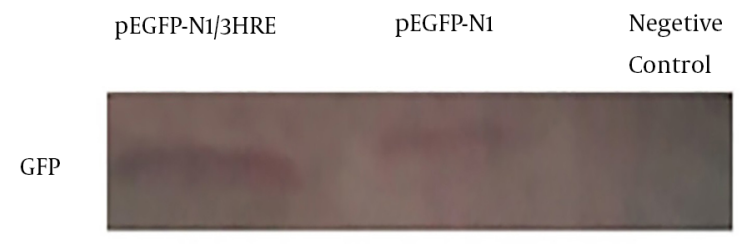

$\beta$-Actin

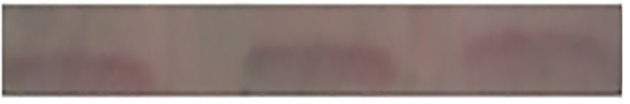

Over expression of BAX was detected in MCF7 cells, when 36 hours after transfection with PEGFP-N1/3HRE, comparing with MCF7 cells that transfection with pEGFP-N1. Negative control was lysate from MCF7 cells.

Solid tumors that are in low oxygen conditions are adopted to hypoxic condition by the help of transcription activation of more than 50 genes. These genes are the main regulator of various aspects, including an angiogenesis, tumorigenicity, metabolism, proliferation, invasion and metastasis (22). Genes that are more active under hypoxic conditions contain regulatory regions called HRE. These regions are HIF-1 binding site, after binding this molecule to HRE regions expression of the gene containing it was increased (23-25). This element (HRE) can be located in upstream or downstream of genes (18).

HIF-1 $\alpha$ expression increase has a direct relationship with tumor progression and malignancy, so that re-

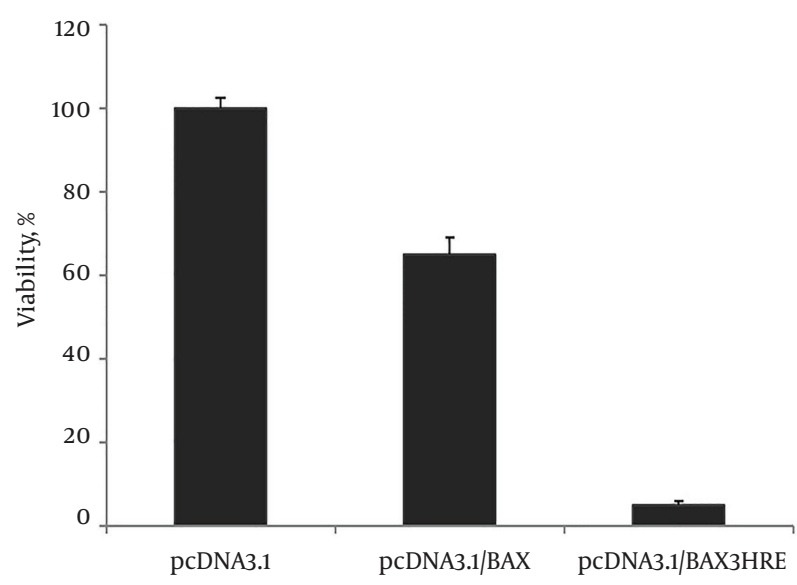

Figure 4. The effect of BAX on cell viability in MCF7 cells.MCF7 cells were treated with pcDNA3.1/BAX and pcDNA3.1/BAX3HRE and incubator in a hypoxia incubator for 36 hours the cell viability was measured with MTT assay. pcDNA3.1 was used as a negative control. Viability is significantly decrease $(\mathrm{P}=0.001)$ in the pcDNA3.1/BAX3HRE compared with pcDNA3.1/BAX $(n=3)$. Student's t-test was used for analysis. Data shown is mean values \pm standard deviation (SD).

searchers have been able to prevent tumor growth by expression decrease in HIF- $1 \alpha$.This result can be shown important of HIF for progression of tumor (23-25). Many studies have been conducted using HRE sequences to improve chemotherapy performance of solid cancers $(26,27)$. For example, a virus using 6 copies of HRE sequence with Mini CMV promoter increased the expression in E1A gene which helped the virus to continue replicating under hypoxic conditions and solved the problem of reducing the replication of the virus in hypoxic conditions (10).

Harada et al. showed that promoter miniCMV containing 5HRE sequence copies increase GFP gene expression up to 500 times under controlled conditions of the amount of HIF-1 in the laboratory (28). Fukui et al. could increase expression of IFN $\alpha 2 b$ in RCC cells and prevented tumor progression through HRE sequence (29). In another study Koshikawa et al. showed increased expression of luciferase gene up to 3 times under hypoxic conditions by the help of HRE sequence (30). In the present study, the results verify the increase of expression of BAX gene about 5 times in MCF7 cell line under hypoxic conditions.

Ingram and Porter have shown that 3 copies of HRE sequence taken from PGK gene lead to increasein gene expression under hypoxic conditions while it had no effect on expression increase under normal oxygen conditions. It worth mentioning HRE sequences were located downstream of gene (18).

One of the main problems of suicide gene therapy is its toxicity caused by using drugs such as Ganciclovir, when the genes producing enzymes metabolizing these drugs 
are used for gene therapy, liver and spleen toxicity is inevitable. However, researchers were able to decrease the toxicity to 1000 times by the help of HRE sequences (9).

Various studies have proved that during cancer the amount of anti-apoptotic proteins are increased in cancer cells and cause the resistance of cancer cells to apoptosis during chemotherapy and radiotherapy. One of the main proapoptotic proteins is BAX protein of bcl-2 family (2). Many researchers have shown that over expression of BAX gene can overcome anti-apoptotic proteins and cause cancer cells' apoptosis $(3,4,31,32)$. In this study it was shown that BAX over expression can lead to apoptosis in cancer cells.

Generally, the results of this study show that HRE sequences plays an important role in expression of its upstream genes in hypoxic conditions, which is a common phenomenon of solid tumors (33). Based on this condition, HRE sequence can be considered as a desirable way in targeting of cancer cells for gene therapy.

\section{Acknowledgments}

This paper was extracted from PhD thesis of Ali Ghanbariasad and financially supported by "Research Department of the School of Medicine, Shahid Beheshti University of Medical Sciences" (Grant No 7817).

\section{Footnotes}

Authors' Contribution: All authors participated in study design, data analysis, interpretation and manuscript writing.

Conflicts of Interest: The authors declare no conflicts of interest in the present study.

Funding/Support: None declared.

\section{References}

1. Yang WS, Park SO, Yoon AR, Yoo JY, Kim MK, Yun CO, et al. Suicide cancer gene therapy using pore-forming toxin, streptolysin O. Mol Cancer Ther. 2006;5(6):1610-9. doi: 10.1158/1535-7163.MCT-05-0515. [PubMed: $16818521]$.

2. Huang J, Gao J, Lv X, Li G, Hao D, Yao X, et al. Target gene therapy of glioma: overexpression of BAX gene under the control of both tissuespecific promoter and hypoxia-inducible element. Acta Biochim Biophys Sin (Shanghai). 2010;42(4):274-80. [PubMed: 20383466].

3. Lowe SL, Rubinchik S, Honda T, McDonnell TJ, Dong JY, Norris JS. Prostate-specific expression of Bax delivered by an adenoviral vector induces apoptosis in LNCaP prostate cancer cells. Gene Ther. 2001;8(18):1363-71. doi: 10.1038/sj.gt.3301531. [PubMed: 11571575].

4. Pirocanac EC, Nassirpour R, Yang M, Wang J, Nardin SR, Gu J, et al. Bax-induction gene therapy of pancreatic cancer. J Surg Res. 2002;106(2):346-51. [PubMed: 12175991].
5. Majumdar AS, Hughes DE, Lichtsteiner SP, Wang Z, Lebkowski JS, Vasserot AP. The telomerase reverse transcriptase promoter drives efficacious tumor suicide gene therapy while preventing hepatotoxicity encountered with constitutive promoters. Gene Ther. 2001;8(7):568-78. doi: 10.1038/sj.gt.3301421. [PubMed: 11319624].

6. Garg H, Salcedo R, Trinchieri G, Blumenthal R. Improved nonviral cancer suicide gene therapy using survivin promoter-driven mutant Bax. CancerGene Ther. 2010;17(3):155-63. doi:10.1038/cgt.2009.63. [PubMed: 19816523].

7. Lee M. Hypoxia targeting gene expression for breast cancer gene therapy. Adv Drug Deliv Rev. 2009;61(10):842-9. doi: 10.1016/j.addr.2009.04.017. [PubMed: 19426773].

8. Chen PY, Ho YR, Wu MJ, Huang SP, Chen PK, Tai MH, et al. Cytoprotective effects of fisetin against hypoxia-induced cell death in PC12 cells. Food Funct. 2015;6(1):287-96. doi: 10.1039/c4fo00948g. [PubMed: 25428606].

9. Binley K, Askham Z, Martin L, Spearman H, Day D, Kingsman S, et al. Hypoxia-mediated tumour targeting. Gene Ther. 2003;10(7):540-9. doi: 10.1038/sj.gt.3301944. [PubMed:12646859].

10. Lu CS, Hsieh JL, Lin CY, Tsai HW, Su BH, Shieh GS, et al. Potent antitumor activity of Oct4 and hypoxia dual-regulated oncolytic adenovirus against bladder cancer. Gene Ther. 2015;22(4):305-15. doi: 10.1038/gt.2014.122. [PubMed: 25588741].

11. Brown JM, Giaccia AJ. The unique physiology of solid tumors: opportunities (and problems) for cancer therapy. Cancer Res. 1998;58(7):1408-16. [PubMed: 9537241].

12. Manohar SM, Padgaonkar AA, Jalota-Badhwar A, Sonawane V, Rathos MJ, Kumar S, et al. A novel inhibitor of hypoxia-inducible factor1alpha P3155 also modulates PI3K pathway and inhibits growth of prostate cancer cells. BMC Cancer. 2011;11:338. doi: 10.1186/1471-2407-11338. [PubMed: 21819554].

13. Ryu YK, Lee JW, Moon EY. Thymosin Beta-4, Actin-Sequestering Protein Regulates Vascular Endothelial Growth Factor Expression via Hypoxia-Inducible Nitric Oxide Production in HeLa Cervical Cancer Cells. Biomol Ther (Seoul). 2015;23(1):19-25. doi: 10.4062/biomolther.2014.101. [PubMed: 25593639].

14. Miyazaki K, Kawamoto T, Tanimoto K, Nishiyama M, Honda H, Kato Y. Identification of functional hypoxia response elements in the promoter region of the DEC1 and DEC2 genes. $J$ Biol Chem. 2002;277(49):47014-21. doi: 10.1074/jbc.M204938200. [PubMed: 12354771].

15. Coulet F, Nadaud S, Agrapart M, Soubrier F. Identification of hypoxiaresponse element in the human endothelial nitric-oxide synthase gene promoter. J Biol Chem. 2003;278(47):46230-40. doi: 10.1074/jbc.M305420200. [PubMed: 12963737].

16. Park J, Park SY, Shin E, Lee SH, Kim YS, Lee DH, et al. Hypoxia inducible factor-1alpha directly regulates nuclear clusterin transcription by interacting with hypoxia response elements in the clusterin promoter. Mol Cells. 2014;37(2):178-86. doi: 10.14348/molcells.2014.2349. [PubMed: 24599003].

17. Fink T, Kazlauskas A, Poellinger L, Ebbesen P, Zachar V. Identification of a tightly regulated hypoxia-response element in the promoter of human plasminogen activator inhibitor-1. Blood. 2002;99(6):2077-83. [PubMed: 11877282].

18. Ingram $\mathrm{N}$, Porter $\mathrm{CD}$. Transcriptional targeting of acute hypoxia in the tumour stroma is a novel and viable strategy for cancer gene therapy. Gene Ther. 2005;12(13):1058-69. doi: 10.1038/sj.gt.3302504. [PubMed: 15800661].

19. Collet G, Lamerant-Fayel N, Tertil M, El Hafny-Rahbi B, Stepniewski J, Guichard A, et al. Hypoxia-regulated overexpression of soluble VEGFR2 controls angiogenesis and inhibits tumor growth. Mol CancerTher. 2014;13(1):165-78. doi: 10.1158/1535-7163.MCT-13-0637. [PubMed: 24170768].

20. Gao H, Huang Z, Shi C, Li H. Construction and detection of the tissue-specific pINV-HPV16 E6/7 vector. Oncol Lett. 2015;9(2):857-62. doi: 10.3892/ol.2014.2736. [PubMed: 25621060]. 
21. Runtuwene J, Amitani H, Amitani M, Asakawa A, Cheng KC, Inui A. Hydrogen-water enhances 5-fluorouracil-induced inhibition of colon cancer. PeerJ. 2015;3:859. doi: 10.7717/peerj.859. [PubMed: 25870767].

22. Chang CC, Shieh GS, Wu P, Lin CC, Shiau AL, Wu CL. Oct-3/4 expression reflects tumor progression and regulates motility of bladder cancer cells. Cancer Res. 2008;68(15):6281-91. doi: 10.1158/0008-5472.CAN-080094. [PubMed: 18676852].

23. Covello KL, Kehler J, Yu H, Gordan JD, Arsham AM, Hu CJ, et al. HIF2alpha regulates Oct-4: effects of hypoxia on stem cell function, embryonic development, and tumor growth. Genes Dev. 2006;20(5):55770. doi: 10.1101/gad.1399906. [PubMed: 16510872].

24. Petrella BL, Lohi J, Brinckerhoff CE. Identification of membrane type-1 matrix metalloproteinase as a target of hypoxia-inducible factor-2 alpha in von Hippel-Lindau renal cell carcinoma. Oncogene. 2005;24(6):1043-52. doi:10.1038/sj.onc.1208305. [PubMed: 15592504].

25. Wang V, Davis DA, Haque M, Huang LE, Yarchoan R. Differential gene up-regulation by hypoxia-inducible factor-1alpha and hypoxia-inducible factor-2alpha in HEK293T cells. Cancer Res. 2005;65(8):3299-306. doi: 10.1158/0008-5472.CAN-04-4130. [PubMed: 15833863].

26. Rankin EB, Giaccia AJ. The role of hypoxia-inducible factors in tumorigenesis. Cell Death Differ. 2008;15(4):678-85. doi: 10.1038/cdd.2008.21. [PubMed: 18259193].

27. Voss MJ, Moller MF, Powe DG, Niggemann B, Zanker KS, Entschladen F. Luminal and basal-like breast cancer cells show increased migration induced by hypoxia, mediated by an autocrine mechanism. BMC Cancer. 2011;11:158. doi: 10.1186/1471-2407-11-158. [PubMed: 21535870].

28. Harada H, Kizaka-Kondoh S, Itasaka S, Shibuya K, Morinibu A, Shi- nomiya $\mathrm{K}$, et al. The combination of hypoxia-response enhancers and an oxygen-dependent proteolytic motif enables real-time imaging of absolute HIF-1 activity in tumor xenografts. Biochem Biophys Res Com mun. 2007;360(4):791-6. doi: 10.1016/j.bbrc.2007.06.149. [PubMed: 17624305].

29. Fukui N, Kageyama Y, Higashi Y, Kihara K, Kizaka-Kondoh S, Hiraoka $\mathrm{M}$, et al. Development of a novel interferon-alpha2b gene construct with a repetitive hypoxia-inducible factor binding site and its suppressive effects on human renal cell carcinoma cell lines in vitro. Int J Clin Oncol. 2014;19(3):497-504. doi: 10.1007/s10147-013-0568-Z. [PubMed: 23739923].

30. Koshikawa N, Takenaga K, Tagawa M, Sakiyama S. Therapeutic efficacy of the suicide gene driven by the promoter of vascular endothelial growth factor gene against hypoxic tumor cells. Cancer Res. 2000;60(11):2936-41. [PubMed: 10850440].

31. Honda T, Kagawa S, Spurgers KB, Gjertsen BT, Roth JA, Fang B. A recombinant adenovirus expressing wild-type Bax induces apoptosis in prostate cancer cells independently of their Bcl-2 status and androgen sensitivity.. Cancer Biol Ther. 2002;1(2):163-7.

32. Ozawa T, Hu JL, Hu LJ, Kong EL, Bollen AW, Lamborn KR, et al. Functionality of hypoxia-induced BAX expression in a human glioblastoma xenograft model. Cancer Gene Ther. 2005;12(5):449-55. doi: 10.1038/sj.cgt.7700814. [PubMed: 15706354].

33. Yang L, Cao Z, Li F, Post DE, Van Meir EG, Zhong H, et al. Tumor-specific gene expression using the survivin promoter is further increased by hypoxia. Gene Ther. 2004;11(15):1215-23. doi: 10.1038/sj.gt.3302280. [PubMed: 15141159]. 